
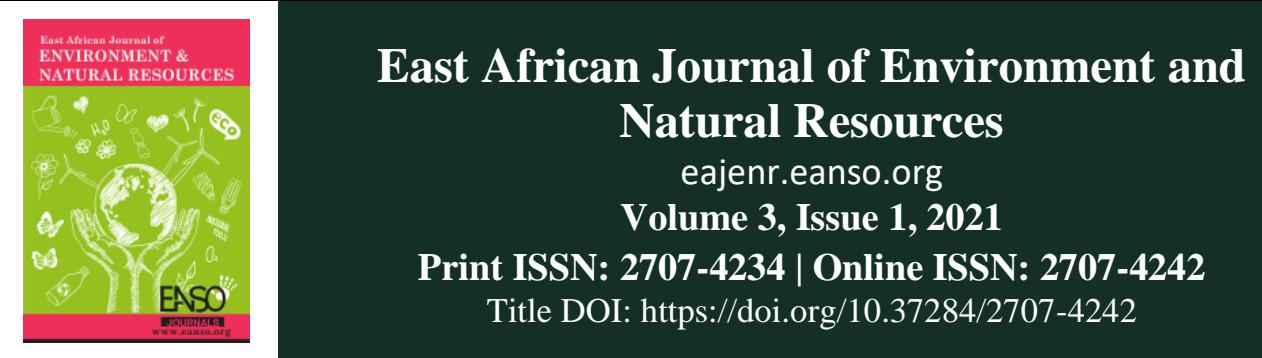

Original Article

\title{
Environmental Conservation, A Factor for Promoting Tourism Industry in Rwanda: A Case Study of Rubavu District.
}

\author{
Prof. Callixte Kabera, $\mathrm{PhD}^{1^{*}} \&$ Dr. Emmy Tushabe, $P h D^{1}$ \\ ${ }^{1}$ University of Tourism, Technology and Business Studies Rwanda, P.O. Box 350, Kigali - Rwanda \\ *Correspondence email: tushabemmy@gmail.com.
}

Article DOI: https://doi.org/10.37284/eajenr.3.1.381

\section{Date Published: ABSTRACT}

11 August 2021 This study sought to examine the contribution of environmental conservation in promoting the tourism industry in Rwanda, the Case study of the Rubavu District

Keywords: using a mixed research design of quantitative and qualitative techniques. The study established that environmental conservation increases the number of tourists that

Conservation, would be hosted in the area; encourages repeat visits of tourists; increases the Environment, satisfaction of tourists and attracts new tourists and retains existing ones in the area.

Tourism However, it experiences some challenges that include, air and water pollution, availability of different rubbish, population growth, and deforestation. These Promotion, become constraints to environmental conservation and the tourism industry Rubavu District, development in Rubavu District. On the other hand, taking preventive measures Rwanda. against air and water pollution, limiting overpopulation, avoiding deforestation and minimizing rubbish have worked to mitigate against the challenges. The study concludes that environmental conservation has played a vital role in promoting the tourism industry in Rwanda. The study recommends that the government of Rwanda in collaboration with the administration of Rubavu District should minimize rubbish by deploying responsible rubbish disposal methods and providing rubbish bins near roads. This will promote cleaner spaces with less environmental stress

\section{APA CITATION}

Kabera, C. \& Tushabe, E. (2021). Environmental Conservation, A Factor for Promoting Tourism Industry in Rwanda: A Case Study of Rubavu District. East African Journal of Environment and Natural Resources, 3(1), 108-118. https://doi.org/10.37284/eajenr .3.1.381

\section{CHICAGO CITATION}

Kabera, Callixte \& Emmy Tushabe. 2021. "Environmental Conservation, A Factor for Promoting Tourism Industry in Rwanda: A Case Study of Rubavu District". East African Journal of Environment and Natural Resources 3 (1), $108-118$. https://doi.org/10.37284/eajenr.3.1.381.

108 | This work is licensed under a Creative Commons Attribution 4.0 International License. 


\section{HARVARD CITATION}

Kabera, C. Tushabe, E. (2021) "Environmental Conservation, A Factor for Promoting Tourism Industry in Rwanda: A Case Study of Rubavu District", East African Journal of Environment and Natural Resources, 3(1), pp. 108-118. doi: 10.37284/eajenr.3.1.381.

\section{IEEE CITATION}

C. Kabera E. Tushabe, "Environmental Conservation, A Factor for Promoting Tourism Industry in Rwanda: A Case Study of Rubavu District", EAJENR, vol. 3, no. 1, pp. 108-118, Aug 2021.

\section{MLA CITATION}

Kabera, Callixte \& Emmy Tushabe. "Environmental Conservation, A Factor for Promoting Tourism Industry in Rwanda: A Case Study of Rubavu District". East African Journal of Environment and Natural Resources, Vol. 3, no. 1, Aug 2021, pp. 108118, doi:10.37284/eajenr.3.1.381.

\section{INTRODUCTION}

Worldwide tourism is a fast-growing industry. It has vital importance in the economy of a nation. However, without the conservation of the environment, tourism cannot adequately yield the desired outcomes. Tourism has become remarkable in both developed and developing economies across the world which significantly contributes to income generation, employment creation, and poverty elimination (Andriotis et al., 2012). The tourism sector has become an increasingly important industry for many developed and developing countries as a source of revenue as well as a source of employment. The tourism industry cannot succeed without taking effective and real consideration of the environmental dimensions. That is why environmental conservation is paramount in tourism industry development. Sustainable or Eco-tourism development currently, is receiving much attention from inbound/international and national tourism organizations. Therefore, in many countries, laws require a certain standard level in relation to environmental sustainability and conservation before a tourism business can be opened (Simmons, 2014). On the other hand, people nowadays are more aware of environmental conservation than they were before. People are very aware of how environmental conservation is a major factor for promoting the tourism industry, as they are investors in the tourism industry, they want their investment to be in a well-conserved and sustained environment. Normally, Environmental conservation in the country motivates people to take investment decisions in the tourism sector (Neto, 2013)
In African countries, tourism provides major economic development opportunities and is a means of improving the livelihoods of residents. Therefore, local governments in Africa are required to improve and maintain destination areas and set measures for proper environmental conservation. Local authorities and governments, despite their political orientation, see tourism as a way to develop the country's economy. From this assumption, they strive to conserve and protect the environment properly and come up with images that could be used for tourism industry development, this contributes to both local income generation and economic growth (Liu, 2013). Tourism is important and countries see it as the only way the preservative natural destinations or areas. In many tourism projects, the conservation of the natural, cultural, and built environment is an important motivation for the beginning of the project. The standard of the environment, both natural, artificial/ man-made, or cultural is core to tourism. Conservation of the environment and sustainable use of natural resources can attract visitors to come to the host country and stay longer; they feel comfortable as they are in their own homes. Governments in Africa and East Africa, in general, should assist the tourism industry to develop by providing the infrastructure (transport and accommodation) and educational requirements for tourism, establishes the regulatory environment in which tourism business operates, and take an active role in promotion and marketing (Binns, 2012)

Rwanda's tourism resource base is at risk as a consequence of weaknesses in the system of planning and environmental management. The success of future tourism plans is therefore dependent on the commitment to physical planning and control by Government, district councils, and 
other key stakeholders and a partnership approach being forged between the public and private sectors. Rwanda's tourism industry is environment and nature-based. The conservation and protection of the environment is a priority for all stakeholders in the tourism sector (MINICOM, 2009). In Rwanda, tourism industry development has been acknowledged as a priority to achieve the country's development goals, which are set out in its 'Vision 2020' strategy. Rwanda has made considerable advancement in developing and managing its tourism sector in recent years and this will contribute to the attainment of Vision 2020 objectives and EDPRS targets, through job creation, strengthening professional competencies, local community participation in the development of the sector for their own benefit, improved use of information and communication technology, rational use of existing physical infrastructure and development of new infrastructure, strengthening public-private sector partnerships, and the diversification of sustainable tourism products (MINICOM, 2009). It is envisaged that the new tourism policy will increase revenue figures even further, contributing to tax revenue, boosting the balance of payments, and contributing to sustainable economic growth and equitable distribution of wealth for the benefit of all Rwandans. This should be achieved through proper conservation of the environment (MINICOM, 2009).

Rubavu district is one of the 30 districts of Rwanda located in the Northwest of Rwanda contiguous with Goma the city across the border in the Democratic Republic of Congo, preferable and beautiful in the tourism industry according to the climatic, geographical, and historical features. The district is the home of Lake Kivu and the Virunga mountains which offers visitors attractive mountain scenery and enjoyable moderate climate throughout there. Rubavu features a resort on the shores of Lake Kivu with several hotels and three sandy beaches. The area is also known for water sports. Rubavu district with its northern shore of the lake Kivu on which Goma city and Gisenyi city lies is a flat plain featuring lava formations from the eruptions of nearby Mount Nyiragongo (RDB: Rubavu Map, 2012).

\section{LITERATURE REVIEW}

\section{Concept of Revenue Sharing}

Environmental conservation refers to the protection, preservation, management, or restoration of natural environments and the ecological communities that inhabit them and what surrounds them. Environmental conservation can also be defined as anything done to protect the planet and conserve its natural resources so that every living thing can have an improved quality of life (Cooper \& Wanhill, 2013). Environmental conservation actions help in producing and maintaining adequate utilization of natural resources, elimination of air, water pollution, and solid wastage, these have a significant impact on the development of the tourism industry in the destination areas. When Environmental conservation is done properly in destination areas, the tourists feel comfortable as they are at their own homes. Environmental conservation plays a significant role in tourism development as it motivates visitors to come to host countries and stay longer, it helps host countries to attract new tourists and maintain existing ones, it encourages repeat visits, it increases the satisfaction of tourists in the area.

\section{Role of Environmental conservation to tourism industry development in the country}

Increase the tourist numbers that would be hosted in the area: Where there is Environmental conservation, the movement of tourists exist at a satisfactory level; keeping the environment clean is a very important aspect of tourism industry development as this increases the number of tourists that need to be hosted in the area, it is important to focus on this as it is known that the proper environment is paramount in attracting various tourists. Water pollution and rubbish are considered to be two of the main cause of the environment being dirty (Barbosa, 2015). The natural environment is a habitat where humans as well as (Flora and fauna) plants and animals live. Keeping it clean and neat is our responsibility. It is necessary to keep the environment clean because through it there is fresh air; air and water pollution are reduced etc. An unclean environment leads to a bad condition of a society, the arrival of diseases, and many more, as result, the tourists will not visit the 
area and the tourism industry as a whole will not be developed as required. However, the lack of environmental conservation affects negatively the tourism industry development since this discourages various tourists to visit. An unclean environment prevents tourists from feeling comfortable and as a result, will not visit the area again. Consequently, they will switch to other countries in the region which offer similar tourists attractions with proper Environmental conservation, hence poor tourism industry development (Raymond, 2015). Due to the lack of environmental conservation in host areas, the movement of tourists between their place of origin and their destinations is impeded and this hampers the expansion of the tourism industry. However, in the area where natural resources are properly maintained and protected, the tourism industry is developed because they attract many tourists (Mohd, 2016).

Encouraging repeat visits of tourists: Tourists who are satisfied with the environment of the visited area have a high probability of coming again to visit the area on different occasions and this is a relevant issue which is helpful to get the overall tourism industry development; therefore, a high level of environmental conservation will decrease the perceived need of tourist to switch to other countries in the region which offer similar tourists attractions, thereby increasing tourist repeat visit, hence effective development of tourism industry in the area. In order to achieve tourists satisfaction, host countries need to maintain and protect the environment properly which resultantly motivates tourists to continue doing repeat visits on an ongoing basis; for host countries to be able to achieve repeat visits by tourists in the increasingly competitive tourism businesses, they should organize their tourism operations and conserve environment according to the needs expressed by their tourists. They should provide tourism services or products that meet or even exceed tourists' expectations, this leads to the performance of the tourism industry (Mostafa, Sadegh, \& Zainab, 2010).

Increase the satisfaction of tourists: Environmental conservation in the country can play a very important role in winning tourists' hearts and minds; keeping it clean and neat is our responsibility in order to satisfy existing tourists and attracts new ones (Raymond, 2015). Satisfied tourists with the products and services received in the host country always suggest others to visit the country while dissatisfied customers will also recommend others in huge numbers but in the context of negative marketing, most probably dissatisfied tourists recommend others not to visit the country. A country seeking to maximize tourist satisfaction has realized that good environmental conservation helps a country to be visited by many tourists. Poor Environmental conservation causes tourists to be unsatisfied and leave a country with negative word of mouth to prospective tourists. The more a country conserve its environment, the more it builds strong tourist relations, the more tourist is satisfied and the more it increases repeat visit of tourists, hence, tourism industry development and expansion. For a country to develop the tourism industry properly; it should provide tourism services or products that meet or even exceed tourists' expectations, proper Environmental conservation makes tourists feel happy and comfortable as they are at their own home, this encourages them to come to a host country in different occasions (Cooper \& Wanhill, 2013).

The attraction of new tourists and retention of existing ones in the area: The conservation of the natural, cultural, and man-made environment is an important motivation for the initiation of the tourism project. Tourism is positive where the conservation of natural areas is properly maintained. When natural resources are maintained, the tourists will visit the area abundantly. However, without the conservation of the environment, tourism cannot adequately yield the desired outcomes. To meet tourism demand and achieve the sustainable development of the tourism industry, it is necessary to develop a range of quality tourism products and services and conserve the environment properly, in order to attract new tourists and maintain existing ones and try to meet the needs of international, regional and domestic visitors (Muhanna, 2006). With proper Environmental conservation in the host country, the number of tourists' arrivals from different world regions increases constantly, they tend to come to host countries on different occasions and stay longer. However, poor environmental conservation hinders long-term tourism growth and the general progress of tourist destinations in providing the required 
services to tourists. With poor Environmental conservation, tourists needs and desires will not be met and this will prevents tourists from getting total satisfaction in the host areas and they will tend to switch to other countries in the region which offer similar tourist attractions (Sonja \& Ivana, 2016)

\section{Challenges to Environmental conservation towards tourism industry development the country}

Air and water pollution: Air pollution is the contamination of air by various pollutants releases from industries, forests, and some toxic gases. Air pollution is caused by a number of sources and human activities such as industry and transport and can have a detrimental effect on public health and the environment. Air pollution is said to be a problem at the local, national and international levels and it has a negative impact on tourism industry development as it limits the number of tourists who would visit the host country and stay longer. Among other negative effects of air pollution is the environment and affects everyone: humans and their habitats, animals, crops, cities, forests, aquatic ecosystems. It is fact that air pollution is caused by the presence of toxic substances in the atmosphere, mainly produced by human activities like industrialization, even though sometimes it can result from natural phenomena like dust storms volcanic eruptions, and wildfires, etc... Air pollution is indeed a significant risk factor for human health conditions, causing allergies, respiratory and cardiovascular diseases as well as lung damage (Barbosa, 2015). Whereas water pollution is the contamination of the water body by various pollutants releases from sewages, chemical waste from industries, household waste, etc.

Water pollution refers to the contamination of a river, a stream, ocean, lake, or any other stretch of water, depleting water quality and making it toxic for the environment and humans. Water pollution truly harms biodiversity and aquatic ecosystems. And as matter of fact, toxic chemicals change the colour of water thus increase the number of minerals known as eutrophication which has a bad impact on life in water. Thermal pollution, defined by a rise in the temperature of water bodies, contributes to global warming and causes serious hazards to water organisms (Olaniran, 2014). In addition, water pollution has very negative effects on public health. Drinking contaminated water leads to a lot of diseases such as cholera, diarrhoea, typhoid, dysentery, or skin infections. In areas where there is no good drinking water, the main effect is dehydration. With water pollution, the tourism industry cannot be developed as needed because it limits tourists to visit the area. Fish, birds, and wildlife depend on clean water. The absence of clean water makes them migrate, or die hence leaving the site with its potential for tourism attractions. (Vasenina, 2013)

Availability of different rubbish: People most of the time throw litter and dust on the footpaths and roads instead of throwing it in dustbins. Hence slowly it accumulates and transforms into huge garbage and its negative effects affect the population. If this garbage is not cleaned, further it smells stink (unpleasant odour) and welcomes the diseases and then people are affected by it. Thus, if we do not keep our environment clean there would be many consequences or problems which will be faced by society and people that live in that environment. Many types of rubbish in the area cause the environment to be dirty and this does not attract tourists, dirty place prevents tourists to feel comfortable as they are at their own home. The Availability of rubbish in destinations areas affects negatively the tourism sector; this reduces the attractiveness of destinations and the tourism sector's competitiveness (Mohd, 2016).

Deforestation; Tourism also has the capacity to generate and spread incomes and has strong spill over effects for poverty reduction through stronger linkages. Strong linkages catalyze a multiplier effect that can generate broad-based economic benefits at the national level, as well as in situ employment opportunities and poverty reduction at the local level. In many African countries, however, tourism linkages remain weak due to deforestation and other environmental degradation (Kuvan, 2015). Deforestation means the term cutting down of trees or felling and cutting/clearing of tree plantations or forest cover so as to have industrial or urban and agricultural use. Deforestation leads to the removal of forest cover to enable land available for commercial, residential, or industrial purposes. More so deforestation affects the climate in a couple of ways for instance trees let out water vapour in the 
air, which affects the environment and the tree cover. Tree cover provide the needed shade that enables the soil to retain moisture. The consequence is the imbalance in the atmospheric temperature thus making ecological conditions difficult. Deforestation can be caused by agricultural activities, logging, urbanization, forest fires, etc.... deforestation limits the arrival of tourists because there are no sufficient forests to be visited in the country (Cooper \& Wanhill, 2013).

Population growth has had a negative impact on the quality of the environment. As more land is used for agriculture or living purposes, the environment changes drastically and tourism activities cannot be developed. As the population of humans grows in certain cities or rural areas, more resources must be used to maintain the well-being of the population and this prevents tourism activities to be sustained (Kahn \& Hardley, 2017). As the population increases, there is an increase in the amount of pressure put on the agricultural sector. Farming is a fundamental human activity that changes the landmasses and it's one way human beings have affected negatively the environment. More so, as the population continues to grow, more advanced technologies and practices will automatically be implemented and as result increase agricultural harvest. "As a result, a lot of industrial fertilizers, pesticides, chemicals, and countless other products will continue to produce waste products of all types". As humanity continues to use these waste products, it will increase dead zones in pools, lakes, and rivers. As dead zones increase, it's likely fishes and other marine organisms start to die often frequently. This will lead to cascading events that will negatively impact the marine environments and the quality of water (Shen \& Thomas, 2015). Population growth plays a key role in environmental destruction. It can lead to deforestation, air, and water pollution. These have a negative effect on the environment and also impact human daily lives, they stop many tourists to visit the area. In addition, the main problems facing the environment are pressures from the growing population on the natural resources such as land, water, flora and fauna, and other non-renewable resources, these limit the tourism industry to get developed properly (Barbosa, 2015). When population growth continues to rise in the country, some tourism areas will be occupied by people and tourist movements will be reduced in the country. Excessive population growth prevents has negative effects on natural resources; this prevents tourism industry development in the country.

\section{Solutions for better environmental conservation towards tourism industry development the country}

Limit the overpopulation: The tourism industry can achieve its effective development where measures for population pressure are reduced. Strategies to limit overpopulation can facilitate many forests and other tourism sites to grow up. As strategies to limit population pressure are taken; the tourism industry is developed and this can be an engine for inclusive growth and sustainable economic development (Preston, 2016). Note that, experience has proved that when women are empowered and given authority to control their own reproduction and have access to quality education and basic social services, the average number of births per woman drops slowly. The population growth rate should be stopped through effective family planning and other measures. Illiteracy, malnutrition, and diseases, and the negative effects of population growth and awareness of the population need to be carried out. Population growth refers to the increase in the number of people living in a geographical area. Since populations can grow exponentially, natural resource reduction can occur rapidly, leading to specific environmental degradation which has a negative impact on tourism industry development (Melissa, 2018).

Limiting deforestation: One of the best measures to curb down deforestation is to reduce the cutting felling of trees, by applying a series of rules and laws to control it. Cutting of trees must be replaced by planting young trees to replace the older ones that were cut to have a clean environment. As deforestation is reduced, forests grow up abundantly and this increases tourists in the country (Kuvan, 2015). Worldwide forests are the principal resources used for the construction of tourist facilities, tourism activities depend on forests and other natural areas. Investments in reducing deforestation have a significant impact on tourism development. Keeping forests undamaged also helps prevent floods and drought by regulating regional rainfall. It must be noted that Forest 
conservation means preservation and the protection of forest cover and its living organisms. The preservation of all-natural resources is absolutely essential for the development of the tourism industry (Melissa, 2018). While deforestation cannot be avoided completely, there is a need to control it. Trees that are still young and immature have not to be felled instead protected. Avoiding large-scale commercial deforestation must be avoided and practices such as selective cutting or clear-cutting will be beneficial in the long run for tourism sustainability. Deadly forest loss is mostly caused by fires as a result of natural causes or accidentally caused by man or even intentional in some cases. (Kuvan, 2015)

Minimizing rubbish: Rubbish is bad for the environment. It wastes our natural resources, a country or other area with a lot of rubbish does not attract foreign visitors because they feel uncomfortable. However, the first solution to minimize rubbish is to always make sure you properly dispose of your rubbish; Recycle all that can be recycled and put all other garbage in the proper containers and dustbins. For instance, if a friend throws rubbish on the ground, ask them to put it in the rubbish where it is supposed to be. If you see a piece of litter, pick it up and throw it away. But remember, never touch anything that you are not sure of-it may be sharp or be a hazardous material (Juan, 2015). Rubbish causes serious environmental consequences, so it is up to us to be responsible for the waste we create. You can help by actively creating less waste, picking up litter when you see it, and encouraging others to fight to litter and this will help us to live in a clean environment able to attract various visitors. By using responsible rubbish removal, you will get to enjoy a cleaner space with less stress. In addition, for proper rubbish removal, there is a need to use a rubbish removal company specialized in the proper disposal of waste if citizens do not have the necessary skills and resources to do it themselves (Olaniran, 2014).

To protect our environment and attract various visitors, we need to reduce wastes by putting them in the area reserved for rubbish; we can also avoid buying things with too much packaging, governments should set penalties for those who do not dispose of rubbish properly, governments can also encourage industries to reduce waste, they should charge a tax based on the amount of waste produced (Melissa, 2018). Rubbish has an extremely negative impact on the environment. Rubbish tends to damage areas where we live, work, and where children play. The range of factors is due to what people do, while others are from areas of manufacturing and others and all kinds of rubbish have a negative effect on everything. People or animals can get sick or even die because of careless mistakes of non-removal of rubbish that happen in this world every day. So please, be aware of the all of the consequences of rubbish and help keep our planet clean, the clean country, increases the number of tourists, because they feel as they are at their own home, this motivates them to visit the country in different occasion, hence tourism industry development (Olaniran, 2014).

\section{RESEARCH METHODOLOGY}

Given the nature of the study, the study used a mixed research design employing both qualitative and quantitative approaches. Both primary and secondary sources were used to obtain data from respondents. Primary sources included two focus group discussions, interviews from key informants, and self-administered structured and semistructured questionnaires. The secondary sources involved document review of the reports and other related documents from RDB, tourism associations, and the chamber of tourism. The results of this exercise guided the subsequent phase which involved a series of key informant interviews of the management and staff of RDB and the Rubavu district authorities. The study respondents were selected from the administrative district of Rubavu. The total population of the study was 400 but the study sampled only 196 key figures including respondents considered adequate to provide reliable data determined using (Kreijcie \& Morgan, 1970). The population size for this study was 400 people including 300 local community members from Gisenyi and Nyamyumba Sectors, 10 local leaders at the district level, and 90 tourists. The sample included; 26 local leaders at the district level, 104 local community members from Gisenyi and Nyumyumba sectors, 66 tourists. The study also employed a focus group discussion with community leaders and key stakeholder organizations. The researchers used excel as well as SPSS to analyze data into meaningful information. However, the 
data gathering faced hardships such as the terrain of the park the rugged landscape made the data collection burdensome, communicating with the local communities was not easy due to the fact that they were spread along the park, did not understand English hence creating a language bottleneck.

\section{RESULTS}

The study was undertaken to achieve and to answer a variety of questions which included What is the role of environmental conservation to tourism industry development in Rubavu District? What are the challenges to Environmental conservation towards tourism industry development in Rubavu District? and What are solutions for better environmental conservation towards tourism industry development in Rubavu District? Literature was reviewed, data was collected, analysed and eventually presented in tables, figures and narrative.

Table 1: The role of environmental conservation to tourism industry development in Rubavu District

\begin{tabular}{lll}
\hline Roles & Frequency & Percentage \\
\hline Increases the tourist numbers that would host in the area & 70 & 35.7 \\
Encouraging repeat visits of tourists & 55 & 28 \\
Increases the satisfaction of tourists & 50 & 25.5 \\
Attraction of new tourists and retention of existing ones in the area & 21 & 10.7 \\
Total & $\mathbf{1 9 6}$ & $\mathbf{1 0 0}$ \\
\hline
\end{tabular}

Source: Field data, 2020

Findings reveal that $35.7 \%$ of respondents reported that Environmental conservation increases the tourist numbers that would host in the area; this implies that where there is environmental conservation, the movement of tourists exists at a satisfactory level; keeping the environment clean is a very important aspect of tourism industry development as this increases the number of tourists that need to host in the area, this finding echoes the study by Juan (2015) which confirmed that indeed environmental conservation increases tourist numbers in a tourism destination since tourists see it as a green and safe environment.

$28 \%$ answered environmental conservation encourages repeat visits of tourists. this implies that host countries, to be able to achieve repeat visits by tourists in the increasingly competitive tourism businesses, should organize their tourism operations and conserve the environment according to the needs expressed by their tourists. This finding is in agreement with the study carried out by (Melissa, 2018) which supports the assertion that due to the benefits of environmental conservation that tourists are likely to come back or even recommend other tourists to come and visit.

$25.5 \%$ said environmental conservation increases the satisfaction of tourists. this implies that proper environmental conservation makes tourists feel happy and comfortable as they are at their own home, this encourages them to come to the host country on different occasions and $10.7 \%$ of respondents agreed that environmental conservation attracts new tourists and retention of existing ones in the area and this implies that where natural resources are properly maintained and protected, the tourism industry is developed because they attract many new tourists. This finding is in agreement with Kahn (2017) who argues that proper environmental conservation retains and attracts tourists since there is an eco-environment.

Table 2: Challenges of Environmental conservation towards tourism industry development in Rubavu District

\begin{tabular}{lll}
\hline Challenges & Frequency & Percentage \\
\hline Air and water pollution & 80 & 40.8 \\
Availability of different rubbish & 40 & 20.4 \\
Poor planning Population growth & 40 & 20.4 \\
Deforestation & 36 & 18.3 \\
\hline
\end{tabular}

115 | This work is licensed under a Creative Commons Attribution 4.0 International License. 


\begin{tabular}{lll}
\hline Total & 196 & 100 \\
\hline
\end{tabular}

Source: Field data,2020

Findings reveal that $40.8 \%$ of respondents said that air and water pollution is a challenge. This implies that with air and water pollution, the tourism industry cannot be developed as needed because it limits tourists to visit the area and this leads to poor development of the tourism industry in the area. This finding can be supported by the study done by Mostafa, (2010) which confirmed that indeed air and water pollution is a challenge and affects tourism industry development. $20.4 \%$ of respondents revealed that the availability of different rubbish is a challenge. This implies that many types of rubbish in the area cause the environment to be dirty and this does not attract tourists, dirty place prevents tourists to feel comfortable as they are at their own home. The Availability of rubbish in destinations areas affects negatively the tourism sector; this reduces the attractiveness of destinations and the tourism sector's competitiveness.

$20.4 \%$ of respondents revealed that there are Poor planning and Population growth that continues to rise in the country, some tourism area will be occupied by people and tourists movements will be reduced in the country. The excessive population has negative effects on natural resources; this prevents tourism industry development in the country and in agreement with the above finding, studies by Preston (2016) asserts that poor planning and population growth if not controlled properly affects the environment thus negatively impacting on sustainable tourism and it's the development and $18.3 \%$ of respondents reported deforestation; this implies that deforestation limits the arrival of tourists because there are no sufficient forests to be visited in the country.

Table 3: Solutions for better environmental conservation towards tourism industry development in Rubavu District

\begin{tabular}{lll}
\hline Solutions & Frequency & Percentage \\
\hline Taking preventive measures against air and water pollution & 100 & 51 \\
Limit the overpopulation & 50 & 25.5 \\
Avoiding deforestation & 30 & 15.3 \\
Minimizing rubbish & 16 & 8.1 \\
Total & $\mathbf{1 9 6}$ & $\mathbf{1 0 0}$ \\
\hline
\end{tabular}

Source: Field data,2020

Findings reveal that $51 \%$ of respondents said that taking preventive measures against air and water pollution is a solution. this implies that taking preventive measures against air and water pollution will reduce the presence of toxic substances in the atmosphere and the contamination of the water body by various pollutants released from sewages, chemical waste from industries, household waste, etc and this will lead to the proper development of tourism industry in the area. This finding echoes with the study done by Sonja, (2016) which confirms for environmental conservation to be achieved, there is a need to take preventive measures against air and water pollution. $25.5 \%$ of respondents revealed that limiting overpopulation is a solution, this implies that the tourism industry can achieve its effective development where population pressure is reduced. Strategies to limit overpopulation can facilitate many tourism sites to grow up and this has a significant impact on tourism industry development. The same finding is echoed by studies done by Raymond (2015) \& Sounders (2007) who also emphasized that for environmental conservation to occur, there is a need to limit population since increased population affects the environment.

$15.3 \%$ of respondents revealed that among the alternative solutions is avoiding deforestation, this implies that worldwide forests are the principal resources used for the construction of tourist facilities, tourism activities depend on forests and other natural areas. Investments in reducing deforestation have a significant impact on tourism industry development. As deforestation is reduced, 
forests grow up abundantly and this increases tourists in the country and $8.1 \%$ opted for minimizing rubbish as the solution. this implies that by using responsible rubbish removal, you can get to enjoy more clean space with less stress, this can increase the number of tourists because they feel as they are at their own home, this motivates them to visit the country on a different occasion, hence tourism industry development. In agreement with the above finding, studies by WTO (2012) assert that minimizing rubbish is the optimal mitigation for promoting sustainable environmental conservation and ensuring that tourists come in to visit a tourism destination.

\section{CONCLUSION}

After data analysis and interpretation, the study came up with the following conclusions:

Based on the findings of this study, it was concluded that conservation of the environment is an important factor that influences the promotion of the tourism industry since when it is made properly in destination areas, the tourists feel comfortable as they are at their own homes. Environmental conservation has a significant contribution to tourism industry development as it increases the tourist numbers that would host in the area; it encourages repeat visits of tourists; it increases the satisfaction of tourists and it attracts new tourists and retains existing ones in the area. Without the conservation of the environment, tourism cannot adequately yield the desired outcomes; meaning that the tourism industry cannot succeed without taking effective and real consideration of the environmental dimensions.

\section{RECOMMENDATIONS}

Findings revealed that air and water pollution is a challenge to Environmental conservation towards tourism industry development in Rubavu District, therefore the government of Rwanda together with the administration of Rubavu District should take preventive measures against air and water pollution; this will reduce the presence of toxic substances in the atmosphere and the contamination of the water body by various pollutants released from sewages, chemical waste from industries, household waste, etc and this will lead to the proper development of tourism industry in the area.
The study also recommends that the government of Rwanda in collaboration with the administration of Rubavu District should limit the overpopulation by taking strong strategies to limit overpopulation, this can facilitate many tourism sites to grow up and this has a significant impact on the tourism industry development. The tourism industry can achieve its effective development where population pressure is reduced.

\section{REFERENCES}

Andriotis, K., George, A., \& Athanasios, M. (2012). Measuring tourist satisfaction: A factor-cluster segmentation approach.

Barbosa, M. E. (2015). Environmental conservation, tourism and economic development: an avant-garde Brazilian solution through Public-Private Partnerships (PPPs). Published on Infrastructure and Public-Private Partnerships.

Binns, T. (2012). 'Tourism as a Local Development Strategy in South Africa'. The Geographical Journal, 168(3): 235-274.

Cooper, C., \& Wanhill, S. (2013). Tourism Development Environmental and Community issues.London. UK. Wiley Publishing.

Juan. (2015). How Does Littering Affect the Environment? retrieved from https://www.airfilters.com/blog/how-doeslittering-affect-the-environment/.

Kahn, J., \& Hardley, J. (2017). “As China Roars, Pollution Reaches Deadly Extremes." New York Times. N.p., 6 Apr. 2017.

Kothari, R. C. (2005). Research MethodologyMethods and Techniques. Third Edition. New Delhi: Wiley\& Sons Limited.

Kuvan, Y. (2015). The use of forests for the purpose of tourism: the case of Belek Tourism Center in Turkey. Journal of Environmental Management, Volume 75, Issue 3, Pages 263-274.

Liu, Z. (2013). Sustainable Tourism Development: A Critique. Journal of Sustainable Tourism, 11(6), 459-475. 
East African Journal of Environment and Natural Resources, Volume 3, Issue 1, 2021

Article DOI: https://doi.org/10.37284/eajenr.3.1.381

Melissa, M. (2018). What Are Environmental Problems Due to Population Growth? https://sciencing.com/effects-humanintervention-environment-23067.html.

MINICOM. (2009). Rwanda Tourism Policy. Kigali.

Mohd, B. B. (2016). Importance of keeping the environment clean/, Class 9 (Student blogger, FHS Publishing club).

Mostafa, M., Sadegh, R., \& Zainab, K. (2010). The concept of competitiveness in the erea of tourism. International Graduate Tourism Research Conference, Kuala Lumpur, Malaysia.

Muhanna, E. (2006). "Sustainable Tourism Development and Environmental Management for Developing Countries". Problems and Perspectives in Management, 4(2),14-30.

Neto, F. (2013). A New Approach to Sustainable Tourism Development: Moving Beyond Environmental Protection. New York: United Nations.

Olaniran, N. S. (2014). "Environment and Health: An Introduction”, in Olaniran, N.S. et al (Ed) Environment and Health.

Preston, S. H. (2016). “The Effect of Population Growth on Environmental Quality." Population Research and Policy Review, vol. 15, no. 2, 1996, pp. 95-108., www.jstor.org/stable/40230088.

Raymond, S. (2015). Tourism Development in Least Developed Countries: Challenges and Opportunities.

Saunders, M., Lewis, P., \& Thornhill, A. (2007). Research Methods for Business Students, 4th ed. Harlow, England.: Pearson Education Ltd.

Sekaran, U., \& Bougie, R. (2013). Research Methods for Business - A Skill Building Approach. 6th ed. United Kingdom: John Wiley \& Son Ltd.

Shen, \& Thomas, T. (2015). Industrial pollution prevention. Berlin: Springer, 2015. Print.
Simmons, D. G. (2014). Community participation in tourism planning. Tourism Management, 15(20), 98-108.

Sonja, J., \& Ivana, I. (2016). Infrastructure as important determinant of tourism development in the countries of southeast Europe. Ecoforum, Vol.5,1(8).

Vasenina, K. (2013). How Water Pollution Impacts Tourism Industries. Retrieved from http://www.bluecommunity.info/view/blog/5232 $46 e f 0 c f 264 a b c c d 292 e b$.

WTO. (2012). Basic References on tourism statistics. Madrid, Spain: WTO.

118 | This work is licensed under a Creative Commons Attribution 4.0 International License. 